\title{
Analytical Model of Cage Induction Machine Dedicated to the Study of the Inner Race Bearing Fault
}

\author{
Marouane Hadjami ${ }^{1}$, Hubert Razik ${ }^{2}$, Mohamed El Kamel Oumaamar ${ }^{3}$, Abdelmamek Kezzar ${ }^{4}$ \\ 1,3,4 Laboratoire d'électrotechnique de Constantine, Département d'électrotechnique, Université Constantine 1. 25000, \\ Constantine, Algeria \\ ${ }^{2}$ Laboratoire Ampère CNRS, UMR 5005, Université Claude Bernard Lyon 1, France
}

\begin{tabular}{l} 
Article Info \\
\hline Article history: \\
Received Sep 9, 2017 \\
Revised Dec 25, 2017 \\
Accepted Jan 10, 2018 \\
\hline
\end{tabular}

Keyword:

Analytical model

Fault diagnosis

Induction machine

Inter bearing raceway defect

Dynamic eccentricity

\begin{abstract}
This paper presents a new analytical model for inner bearing raceway defect. The model is based on the presentation of different machine inductances as Fourier series without any kind of reference frame transformation. The proposed approach shows that this model is able to give important features on the state of the motor. Simulation based on spectral analysis of stator current signal using Fast Fourier Transform (FFT) and experimental results are given to shed light on the usefulness of the proposed model.
\end{abstract}

Corresponding Author:

Hadjami M,

Laboratoire d'électrotechnique de Constantine,

Département d'électrotechnique,

Université Constantine 1.25000,

Constantine, Algeria.

Email: Mhadjami@yahoo.fr

Copyright $@ 2018$ Institute of Advanced Engineering and Science. All rights reserved.

\section{INTRODUCTION}

Electric Power Research Institute (EPRI) carried out a large survey on faults in induction motor in 1985. Bearing faults contain over $40 \%$ of all machine failure. For this reason, the detection of bearing faults has been an important research area [1-6].The different faults occurring in a rolling-element bearing can be classified according to the damaged element as [7]:

a. Outer raceway defect

b. Inner raceway defect

c. Ball defect

d. Cage defect

Bearing faults as all other induction motor failures ought to be diagnosing as early as possible in order to prevent the complete failure of the system and unexpected production costs. For that, the challenge is to have an adequate model of the induction motor which behaves as the real motor, and is able to generate the desired signals as we see in real motors under healthy or faulty state [8], [9], or in motor-pump system [10]. The model for bearing fault proposed by Schoen has been applied in several works as, [11], [12]. Blödt [13] consider this model incomplete, and extended it by the consideration of the torque variations, and the introduction of the radial movement of the rotor center. The fault impact on the airgap length is considered by a series of Dirac generalized functions of vibrations analysis and has been used in Blödt's model [13], [14]. In this approach, one can notice that, firstly, the surface of the Dirac function is equal to 1 , but its amplitude tends towards the infinite one, and that makes the simulation of inductances impossible, and secondly, it's true that the contact angle is considered, but the angle of the defect does not exist. Then, for 
these two raisons, we consider that this approach is not highly reliable. In this work a new approach with taking into account the angle of the defect will be proposed.

In this paper, one of the fourth types of bearing faults classified above is studied, namely the inner race bearing fault, and because the similarity which exists between this last and the dynamic eccentricity fault, a new way for formulating a general model is suggested. The main objective is to offer accurate mathematical formulas of all the inductances of the machine in order to simulate efficiently the behavior of the motor under either healthy and/or faulty conditions.

Bearing faults can be diagnosed with help of many condition monitoring methods such as vibration monitoring [15], [16]. This method is applied with the use of broad band, narrow band and the spectral analysis of the vibration energy of motor. But this method has a drawback of high cost as it requires expensive accelerometers. Thermal monitoring [17]. This method is done by measuring the local and the bulk temperature of motors; it also can be achieved by parameter estimation. This method has a drawback that it might be too slow to detect fault. Current monitoring [18-21]. The method used for diagnosis [22] is accurate and remains one of the most used, but require expensive sensors or specialized tools. For that, and because the stator current harmonics measurement can provide the same indications without requiring access to the motor, in this paper, stator current monitoring is used.

\section{DYNAMIC ECCENTRICITY AND INNER RACE BEARING FAULT}

In $(\mathrm{DE})$, the center of the rotor is not at the centre of the rotation and the position of the minimum air-gap rotates with the rotor (Fig1).

With the same manner used in. The 3D expression of the air gap variation is [23]:

$$
g_{(D y n-e c c)}\left(\theta, \theta_{r}, x\right)=g_{0}\left[1-\delta_{d}\left(1-\frac{x}{l_{(D E)}}\right) \cos \left(\theta-\theta_{r}\right)\right]
$$

And from the approximation for the first harmonic, one can get:

$$
g_{g_{(D y n-e c c)}}^{-1}\left(\theta, \theta_{r}, x\right)=\frac{1}{g_{0}}\left[1+\delta_{d}\left(1-\frac{x}{l_{(D E)}}\right) \cos \left(\theta-\theta_{r}\right)\right]
$$

Figure 1 shows the two types of dynamic eccentricity (uniform and non-uniform)
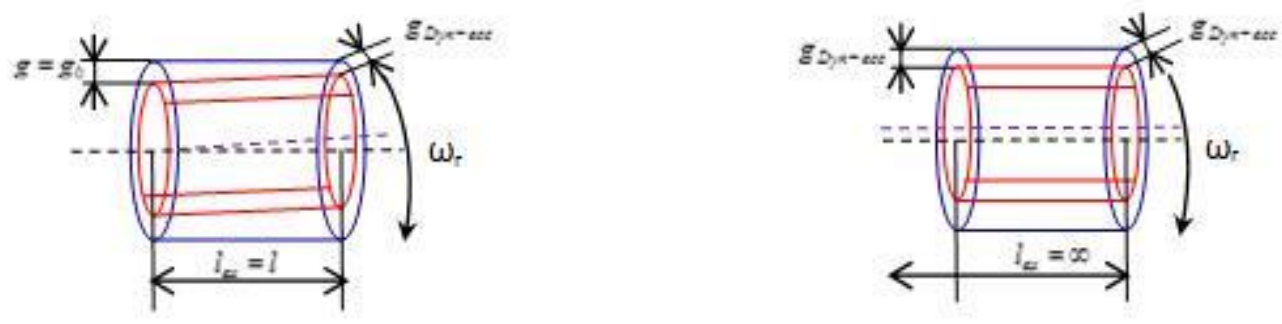

Figure 1. Non uniform (left) and uniform (right) dynamic air gap eccentricity

$\delta_{\mathrm{d}}$ : is the relative degree of eccentricity.

The variation of $\delta_{\mathrm{d}}$ versus the axial position $x$ is:

$$
\delta_{d}(x)=\frac{\delta_{d}}{l} x
$$

The equivalent level of dynamic eccentricity is defined as a function of the axial position $x$ by:

$$
\delta_{d}^{\prime}\left(\theta, \theta_{r}, x\right)=\delta_{d}\left(1-\frac{x}{l_{e x}}\right) \cos \left(\theta-\theta_{r}\right)
$$


If the variation of " $\delta_{\mathrm{d}}$ " versus the axial position $x$ is removed, we return to a $2 \mathrm{D}$ expression.

\subsection{Inner Race bearing Fault}

Bearing is an arrangement of two concentric rings with a set of balls which spin in raceways between the inner ring and outer ring as shown in Figure 2. When a bearing spins, any irregularity in the inner raceway surface generates vibration occuring at periodic frequency, called (BPFI) Ball Pass Frequency of the inner Race, and is created when all the rolling elements roll across a defect in the inner race as shown in Figure 3.

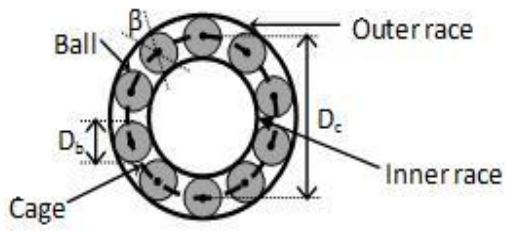

Figure 2. Bearing geometery

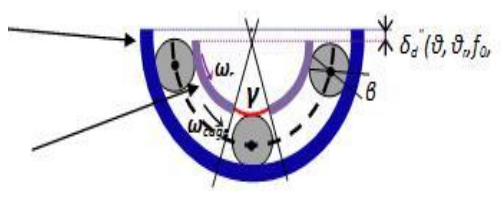

Figure 3. Dynamic eccentricity caused by the inner raceway defect

$\delta_{d}^{\prime \prime}\left(\theta, \theta_{r}, x, f_{0}\right)$ is the equivalent temporary level of eccentricity and $\gamma$ is the defect angle.

Cages function to maintain all the balls at a uniform pitch and rotates at the fundamental cage frequency $\omega_{\text {cage }}$, which is given by [24]

$$
\omega_{\text {cage }}=\frac{1}{2} \omega_{r}\left(1+\frac{D_{b}}{D_{c}} \cos (\beta)\right)
$$

$\beta$ : is the contact angle.

Defect frequency depends upon the bearing geometry and shaft speed $\omega_{r}$. In particular for the inner race, and running at a certain rotor speed $\omega_{r}$, the predictable characteristic fault frequency $f_{\text {int }}$ is [24]:

$$
f_{\text {int }}=\frac{N_{b a}}{2} f_{r}\left(1+\frac{D_{b}}{D_{c}} \cos (\beta)\right)
$$

$N_{b a}:$ The number of balls.

The contact between the balls and the defect caracterised by the angle $\gamma$, generates a temporary static eccentricity. The new way for modelling this fault impact, is the introduction of a digital square wave Figure 4. This signal is expressed as complex Fourier series development.

$$
D_{s w}=\frac{\gamma}{2 \pi}+\frac{2}{\pi} \sum_{\lambda=1}^{\infty} \frac{1}{\lambda} \sin \left(\lambda \frac{\gamma}{2}\right) \cos \left[\lambda\left(\theta_{\mathrm{int}}-\frac{\gamma}{2}\right)\right]
$$

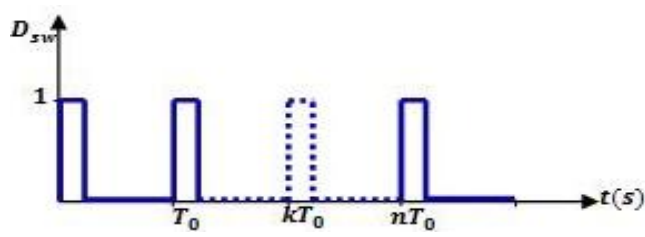

Figure 4. Digital square wave signal

Equations (4) to Equation (7) can be combined into a simplifie expression of the equivalent level of the outer race bearing fault. 


$$
\delta_{d}^{\prime \prime}\left(\theta, \theta_{\mathrm{int}}, x\right)=\frac{\gamma}{2 \pi} \delta_{d}^{\prime}+\frac{\delta_{d}}{\pi}\left(1-\frac{x}{l_{e x}}\right) \sum_{\lambda=1}^{\infty} \frac{1}{\lambda} \sin \left(\lambda \frac{\gamma}{2}\right) \cos \left[\theta-\theta_{r}+\lambda\left(\theta_{\mathrm{int}} \mp \frac{\gamma}{2}\right)\right]
$$

By analogy with (1) and (2), the new formula of the air gap lenght, and the inverse of the air gap function approximated for a small variations, become respectively

$$
\begin{aligned}
& g_{(\text {Dyn-ecc })}\left(\theta, \theta_{r}, x\right)=g_{0}\left[1-\frac{\gamma}{2 \pi} \delta_{d}^{\prime}-\frac{\delta_{d}}{\pi}\left(1-\frac{x}{l_{e x}}\right) \sum_{\lambda=1}^{\infty} \frac{1}{\lambda} \sin \left(\lambda \frac{\gamma}{2}\right) \cos \left[\theta-\theta_{r}+\lambda\left(\theta_{\mathrm{int}} \mp \frac{\gamma}{2}\right)\right]\right] \\
& g_{\left.g_{(D y-\text { ecc }}\right)}^{-1}\left(\theta, \theta_{r}, x\right)=\frac{1}{g_{0}}\left[1+\frac{\gamma}{2 \pi} \delta_{d}^{\prime}+\frac{\delta_{d}}{\pi}\left(1-\frac{x}{l_{e x}}\right) \sum_{\lambda=1}^{\infty} \frac{1}{\lambda} \sin \left(\lambda \frac{\gamma}{2}\right) \cos \left[\theta-\theta_{r}+\lambda\left(\theta_{\mathrm{int}} \mp \frac{\gamma}{2}\right)\right]\right]
\end{aligned}
$$

$\gamma=0$ (Healthy state), $\quad \gamma=2 \pi$ (Dynamic eccentricity), $\quad \gamma \neq 0,2 \pi$ (Inner race bearing fault)

\section{INDUCTANCES CALCULATION}

According to winding function theory, the mutual inductance between any two windings $i$ and $j$ in any electric machine can be developed by [25-27]:

$$
\begin{aligned}
& L_{i j}\left(\theta, \theta_{r}, x\right)=\mu_{0} r \int_{0}^{2 \pi} \int_{0}^{l} n_{i}\left(\theta, \theta_{r}, x\right) M_{j}\left(\theta, \theta_{r}, x\right) g^{-1}\left(\theta, \theta_{r}, x\right) d x d \theta \\
& M^{g}\left(\theta, \theta_{r}, x\right)=n_{j}\left(\theta, \theta_{r}, x\right)-\frac{\int_{0}^{2 \pi} \int_{0}^{l} n_{j}\left(\theta, \theta_{r}, x\right) g^{-1}\left(\theta, \theta_{r}, x\right) d x d \theta}{2 \pi l\left\langle g^{-1}\left(\theta, \theta_{r}, x\right)\right\rangle} \\
& \left\langle g^{-1}\left(\theta, \theta_{r}, x\right)\right\rangle=\frac{1}{2 \pi t} \int_{0}^{2 \pi} \int_{0}^{l} g^{-1}\left(\theta, \theta_{r}, x\right) d x d \theta
\end{aligned}
$$

where $\theta_{r}$ is the angular position of the rotor with respect to the stator frame, $\theta$ is a particular angular position along the stator inner surface, $g^{-1}\left(\theta, \theta_{r}, x\right)$ is termed the inverse air gap function. The terms $n(\theta, \theta r, x)$, $M(\theta, \theta r, x)$ are the turn function and the modified winding function in windings $i$ and $j$ respectively.(the modified winding function theory is used because the non uniformity of the air gap). The model equations of the induction machine are the same as [28].

\subsection{Turn and Winding Rotor Functions}

\subsubsection{Healthy Conditions}

In this case the air gap length $\mathrm{g}$ is uniform and equal to $\mathrm{g}_{0}\left(\delta_{\mathrm{d}}=0\right)$, the turn function, and the winding function of the rotor loop $k$ (with taking into acount the skew angle $\delta_{\mathrm{r}}$ of the rotor bars) are respectively:

$$
\begin{aligned}
& n_{r k}\left(\theta, \theta_{r}, x\right)=\frac{\alpha_{r}}{2 \pi}+\frac{2}{\pi} \sum_{h=1}^{\infty} \frac{1}{h} \sin \left(h \frac{\alpha_{r}}{2}\right) \cos \left[h\left(\theta-\theta_{r}-\left(k-\frac{1}{2}\right) \alpha_{r}+\frac{\gamma_{r}}{l} x\right)\right] \\
& n_{r k}\left(\theta, \theta_{r}, x\right)=\frac{\alpha_{r}}{2 \pi}+\frac{2}{\pi} \sum_{h=1}^{\infty} \frac{1}{h} \sin \left(h \frac{\alpha_{r}}{2}\right) \cos \left[h\left(\theta-\theta_{r}-\left(k-\frac{1}{2}\right) \alpha_{r}+\frac{\gamma_{r}}{l} x\right)\right]
\end{aligned}
$$

$\alpha_{r}$ : The rotor loop opening.

$$
\alpha_{r}=\frac{2 \pi}{n_{b}}
$$


$n_{b}$ : The number of rotor bars.

The variation in the angle $\gamma_{r}$ versus the axial position $x \mathrm{i}$

$$
\delta_{r}(x)=\frac{\delta_{r}}{l} x
$$

\subsubsection{Inner Race bearing Fault}

The modified rotor winding function $M_{r k}\left(\theta, \theta_{r}, x\right)$ can be expressed independently from the value of $p$ as:

$$
\begin{aligned}
& M_{r k}\left(\theta, \theta_{r}, x\right)=N_{r k(\text { healthy })}(\theta)-\frac{\delta_{s}}{\pi}\left(1-\frac{l}{2 l_{e x}}\right) \sin \left(\frac{\alpha_{r}}{2}\right)\left(\sin \left(\frac{\gamma_{r}}{2}\right) /\left(\frac{\gamma_{r}}{2}\right)\right) \cos \left(\theta_{r}+\left(k-\frac{1}{2}\right) \alpha_{r}-\frac{\gamma_{r}}{2}\right) \\
& -\frac{\delta_{s}}{\pi \gamma_{r}}\left(\frac{l}{l_{e x}}\right) \sin \left(\frac{\alpha_{r}}{2}\right)\left(\cos \left(\frac{\gamma_{r}}{2}\right)-\frac{\sin \left(\frac{\gamma_{r}}{2}\right)}{\left(\frac{\gamma_{r}}{2}\right)}\right) \sin \left(\theta_{r}+\left(k-\frac{1}{2}\right) \alpha_{r}-\frac{\gamma_{r}}{2}\right)
\end{aligned}
$$

\subsection{Turn and Winding Stator Functions}

\subsubsection{Healthy Conditions}

As the same as for the rotor $(\delta \mathrm{d}=0)$, the turn and the winding functions are respectively [28]:

$$
\begin{aligned}
& n_{s q}(\theta)=\frac{N_{t} \alpha_{s}}{2 \pi}+\frac{2 N_{t}}{p \pi} \sum_{h=1}^{\infty} \frac{k_{w h}}{h} s \cos \left[h p\left(\theta-\theta_{0}-(q-1) \frac{2 \pi}{3 p}\right)\right] \\
& n_{s q}(\theta)=\frac{N_{t} \alpha_{s}}{2 \pi}+\frac{2 N_{t}}{p \pi} \sum_{h=1}^{\infty} \frac{k_{w h}}{h} s \cos \left[h p\left(\theta-\theta_{0}-(q-1) \frac{2 \pi}{3 p}\right)\right] \\
& \left\{\theta_{0}=\left(N_{e}-1+Q\right) \frac{\pi}{N_{s}}, \alpha_{s}=\frac{2 \pi}{N_{s}} Q, N_{t}=N_{c} N_{e} p, \mathrm{k}_{\mathrm{wh}}=\mathrm{k}_{\mathrm{dh}} \mathrm{k}_{\mathrm{th}}, \mathrm{k}_{\mathrm{dh}}=\sin \left(\frac{h p \pi N_{e}}{N_{s}}\right) / N_{e} \sin \left(\frac{h p \pi}{N_{s}}\right), \mathrm{k}_{\mathrm{th}} \sin \left(\frac{h p \alpha_{s}}{2}\right), \alpha_{r}=\frac{2 \pi}{n_{b}}\right\}
\end{aligned}
$$

were, $\alpha_{s}$ : the stator coil opening, $Q$ : the nuber of slots per pitch turn, $N_{c}$ : the number of the conductor per stator slot, $N_{e}$ : the number of slots per pole and per phase, $N_{t}$ : the number of stator turns in series, and $p$ : is the number of pole pairs.

\subsubsection{Inner race bearing Fault}

One can notice that the modified winding function $\mathrm{M}_{\mathrm{sq}}(\theta)$ is different from the winding function $\mathrm{N}_{\mathrm{sq}}(\theta)$ only in the case of $p=1$.

$$
\begin{aligned}
& M_{s(p \neq 1)}(\theta)=N_{s}(\theta) \\
& N_{s q(p=1)}(\theta)=N_{s q}(\theta)-\frac{2 \mu_{0} r l}{g} \frac{N_{t}^{2} \delta_{d}^{2} k_{w(1)}^{2}}{\pi}\left(1-\frac{l}{2 l_{e x}}\right)^{2}\left[\cos \left(\theta_{0}-(q-1) \frac{2 \pi}{3}\right)\right]^{2}\left\{\frac{\gamma}{2 \pi}+\frac{2}{\pi} \sum_{\lambda=1}^{\infty} \frac{1}{\lambda} \sin \left(\lambda \frac{\gamma}{2}\right) \cos \left[\lambda\left(\theta_{\text {int }}-\frac{\gamma}{2}\right)\right]\right\}
\end{aligned}
$$

\subsection{Derivation of Inductances}

\subsubsection{Healthy Conditions}

Using relation (12) and when the skewing effect is considered, the different inductances have similar formulas as presented without skewing effect [28], except that the stator-rotor mutual inductances are multiplied by a skewing factor $k_{(h)}^{s k e}$ for each harmonic component $h$ :

$$
k_{(h p)}^{s k e}=\sin \left(h p \frac{\gamma_{r}}{2}\right) /\left(h p \frac{\gamma_{r}}{2}\right)
$$




$$
L_{s k q h(\text { healthy })}^{s r}=\sum_{h=1}^{\infty} M_{h}^{s r} s \cos \left[h p\left(\theta_{r}-\theta_{0}+\left(k-\frac{1}{2}\right) \alpha_{r}-(q-1) \frac{2 \pi}{3 p}-\frac{\gamma_{r}}{2}\right)\right]
$$

with $\left\{M_{h}^{s r}=\frac{4 \mu_{0} r l}{g_{0}} \frac{N_{t}}{\pi} \frac{k_{w h}}{h p} k_{h}^{s k e}\right\}$

\subsubsection{Inner race bearing Fault:}

By using (14) one can obtain the different formulas of the stator and rotor inductances. The stator and the stator-rotor mutual inductances are dependent on the value of $p,(p=1$ or $p \neq 1)$.

$$
\begin{aligned}
& M_{r j k(D E)}=-\frac{2 \mu_{0} r l}{g} \frac{1}{n_{b}} \times\left\{\frac{\gamma}{2 \pi}+\frac{2}{\pi} \sum_{\lambda=1}^{\infty} \frac{1}{\lambda} \sin \left(\lambda \frac{\gamma}{2}\right) \cos \left[\lambda\left(\theta_{\mathrm{int}}-\frac{\gamma}{2}\right)\right]\right\} \\
& \times\left\{A\left(\cos \left(\theta_{r k j}-\theta_{r}\right)+\frac{A}{\pi} \cos \left(\theta_{r k}-\theta_{r}\right) \cos \left(\theta_{r j}-\theta_{r}\right)\right)-B\left(\cos \left(\theta_{r k j}-\theta_{r}\right)+\frac{B}{\pi} \cos \left(\theta_{r k}-\theta_{r}\right) \cos \left(\theta_{r j}-\theta_{r}\right)\right)\right\}
\end{aligned}
$$

with:

$$
\left\{\begin{array}{c}
\theta_{r k}=\theta_{r}+\left(k-\frac{1}{2}\right) \alpha_{r}-\frac{\gamma_{r}}{2}, \quad \theta_{r k q}=\theta_{r k}-\theta_{0}-(q-1) \frac{2 \pi}{3 p}, \quad \theta_{r k j}=\theta_{r k}+\frac{1}{2}(j+k-1) \alpha_{r}-\frac{\gamma_{r}}{2} \\
M_{(x)}^{s r}=\frac{4 \mu_{0} r l}{g_{0}} \frac{N_{t}}{\pi} \frac{k_{w h(x)}}{h p} k_{(x)}^{s k e}, \quad \mathrm{~A}=\delta_{d}\left(1-\frac{l}{2 l_{e x}}\right) \sin \left(\frac{\alpha_{r}}{2}\right) k_{(1)}^{s k e}, \quad \mathrm{~B}=\frac{\delta_{d}}{\gamma_{r}}\left(\frac{l}{l_{e x}}\right)\left(\sin \left(\frac{\alpha_{r}}{2}\right) \cos \left(\frac{\gamma_{r}}{2}\right)-k_{(1)}^{s k e}\right)
\end{array}\right\}
$$

$L_{r j k(\text { healthy) }}, L_{s_{1} q_{2(\text { healthy) }}}$ are the inductances given in the case of symmetrical rotor respectively [28].

a. The case of $p \neq 1$ :

$$
\begin{aligned}
& L_{s_{11} q_{2}}=L_{s_{q_{1}} q_{2}(\text { healthy })}
\end{aligned}
$$

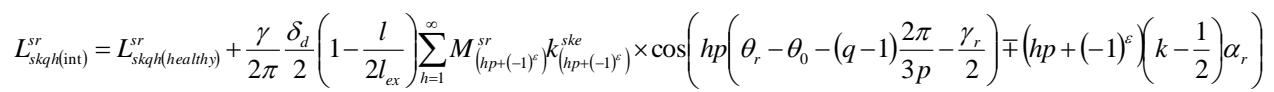

$$
\begin{aligned}
& +\frac{\delta_{d}}{2} \frac{\gamma}{2 \pi}\left(\frac{l}{\gamma_{r} l_{e x}}\right) \sum_{h=1}^{\infty} \frac{M_{(h p+(-1))}^{s r}}{h p+(-1)^{s}}\left(\cos \left(\frac{\left(h p+(-1)^{s}\right) \gamma_{r}}{2}\right)-k_{(h p+(-1))^{s}}^{s k e}\right) \times \sin \left(h p\left(\theta_{r}-\theta_{0}-(q-1) \frac{2 \pi}{3 p}-\frac{\gamma_{r}}{2}\right) \mp\left(h p+(-1)^{s}\right)\left(k-\frac{1}{2}\right) \alpha_{r}\right) \\
& +\frac{1}{\pi} \frac{\delta_{d}}{2}\left(1-\frac{l}{2 l_{e x}}\right) \sum_{h=1}^{\infty} \sum_{\lambda=1}^{\infty} \sin \left(\lambda \frac{\gamma}{2}\right) M_{(h p+(-1))^{r r}}^{s r} k_{\left.(h p+(-1))^{s}\right)}^{s k e} \times \cos \left(h p\left(\theta_{r}-\theta_{0}-(q-1) \frac{2 \pi}{3 p}-\frac{\gamma_{r}}{2}\right) \mp \lambda \theta_{\text {int }} \mp \lambda \frac{\gamma}{2} \mp\left(h p+(-1)^{r}\right)\left(k-\frac{1}{2}\right) \alpha_{r}\right) \\
& +\frac{1}{\pi} \frac{\delta_{d}}{2}\left(\frac{l}{\gamma_{r} l_{e x}}\right) \sum_{h=}^{\infty} \sum_{\lambda=1}^{\infty} \sin \left(\lambda \frac{\gamma}{2}\right) \frac{M_{\left(h p+(-1)^{c}\right)}^{s r}}{h p+(-1)^{\varepsilon}}\left(\cos \left(\frac{\left(h p+(-1)^{\varepsilon}\right) \gamma_{r}}{2}\right)-k_{\left(h p+(-1)^{\varepsilon}\right)}^{s k e}\right) \\
& \times \sin \left(h p\left(\theta_{r}-\theta_{0}-(q-1) \frac{2 \pi}{3 p}-\frac{\gamma_{r}}{2}\right) \mp \lambda \theta_{\text {int }} \mp \lambda \frac{\gamma}{2} \mp\left(h p+(-1)^{\varepsilon}\right)\left(k-\frac{1}{2}\right) \alpha_{r}\right)
\end{aligned}
$$

b. The case of $p=1$ :

For this case, one can use the inductances $L_{s q_{1} s q_{2(D y n-e c c)}=1}^{p=1} L_{k q h_{(D y n-e c c)}}^{s r}$ developed in our old works cited previously, with the same manner as for the case of $p \neq 1$ by adding $\pm \theta_{r}$.

The stator and rotor self magnetizing inductances are respectively $L_{s q i q i}(i=1,2,3)$ and $L_{r j j}\left(j=1: n_{b}-1\right)$.

The different inductances formulas presented for the case of the Inner race bearing fault confirme that, when:

$\gamma=0 \quad \Rightarrow>L_{r j k}=L_{r j k \text { (healthy) }}$

(Healthy state) [28]

$\gamma=2 \pi \quad \Rightarrow>L_{r j k}=L_{r j k(D y n-e c c)}, L_{k q h}^{s r}=L_{k q h_{(D y n-e c c)}}^{s r}$

$\gamma \neq 0,2 \pi=>L_{r j k}=L_{r j k(i n t)}, L_{k q h}^{s r}=L_{k q h_{(i n t)}}^{S r}$

(Dynamic eccentricity) [29] without skew

(Inner race bearing fault)

Figure 5 shows that when the rolling elements roll across a defect in the inner race, a dynamic eccentricity is created at periodic frequency called (BPFI). 
Figure 6 shows the effect of the defect angle on the eccentricity created by the inner race bearing fault on the mutual inductances, and one can notice that the enlarging of the defect angle, involves an increase in the duration of the fault, and if the value of the defect angle is very small (close to zero), the variation in the inductance waveform is almost invisible.

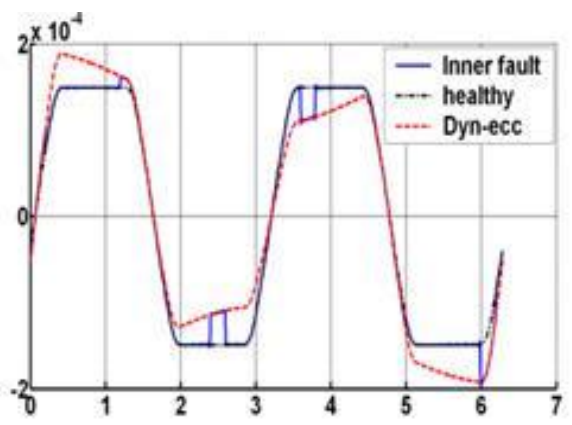

Figure 5. Mutual inductances $\mathrm{L}_{\mathrm{s} 1 \mathrm{r} 1}$ for dynamic variationseccentricity (red) and inner race bearing fault (blue)

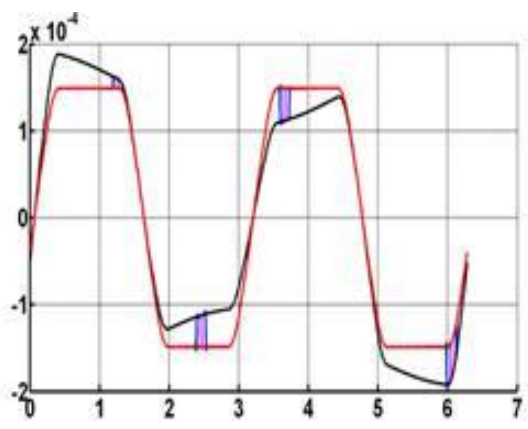

Figure 6. Mutual inductances $\mathrm{L}_{\mathrm{s} 1 \mathrm{r} 1}$ with $\gamma$ and $\delta \mathrm{d}=0.3$ $\left(l_{\mathrm{ex}}=1\right)$

Finally, the Figure 5 and Figure 6 show that inner race bearing fault causes an asymmetrical mutual inductance between stator phases and rotor loops.

\section{INNER RACE BEARING FAULT SIGNATURES IN STATOR CURRENT}

To find in the current of the stator the different signatures of the inner raceway bearing fault, and to understand their origins, it is first necessary to identify the harmonics induced by this defect in the rotor current.For an ideal three-phase supply, the stator's currents which flow in the stator phases are of the form:

$$
\left[I_{s q}\right]=L_{s m} \cos \left(\omega_{s} t-(q-1) \frac{2 \pi}{3}\right)
$$

The derivative of rotor flux in vector matrix form can be written as:

$$
\frac{d}{d t}\left[\psi_{r k}\right]=\frac{d}{d t}\left\{\left[L_{k q h}^{s t}\right]^{T}\left[I_{s q}\right]\right\}+\frac{d}{d t}\left\{\left[L_{r k}\right]^{T}\left[I_{r k}\right]\right\}
$$

Where:

$\omega_{s}:$ is the main voltage supply pulsation

$\left[L_{r_{k}}\right]$ : is the rotor loop inductances matrix

$\left[\begin{array}{c}L_{k_{q} h}^{s r} \\ :\end{array}\right]:$ is the stator to rotor mutual inductances matrix

Since the skewing of the rotor bars does not generate any new harmonics, so the study will be made with the mutual stator-rotor inductance without skewing effect, and which can be expressed as follows:

$$
\begin{aligned}
& L_{s k q h(\mathrm{int})}^{s r}=L_{s k q h(\text { healthy })}^{s r}+\frac{\gamma}{2 \pi} \frac{\delta_{d}}{2}\left(1-\frac{l}{2 l_{(e x)}}\right) \sum_{h=1}^{\infty} M_{\left(h p+(-1)^{\varepsilon}\right.}^{s r} \times \cos \left(h p\left(\theta_{r}-\theta_{0}-(q-1) \frac{2 \pi}{3 p}\right) \mp\left(h p+(-1)^{\varepsilon}\right)\left(k-\frac{1}{2}\right) \alpha_{r}\right) \\
& +\frac{1}{\pi} \frac{\delta_{d}}{2}\left(1-\frac{l}{2 l_{(e x)}}\right) \sum_{h=1}^{\infty} \sum_{\lambda=1}^{\infty} \sin \left(\lambda \frac{\gamma}{2}\right) M_{\left(h p+(-1)^{c}\right.}^{s r} \times \cos \left(h p\left(\theta_{r}-\theta_{0}-(q-1) \frac{2 \pi}{3 p}\right) \mp \lambda \theta_{\mathrm{int}} \mp \lambda \frac{\gamma}{2} \mp\left(h p+(-1)^{\varepsilon}\right)\left(k-\frac{1}{2}\right) \alpha_{r}\right)
\end{aligned}
$$

After development of rotor flux derivative and some simplifications we get:

$$
\left[I_{r k}\right]=\left\lfloor I_{r k(1 h)}\right\rfloor+\left\lfloor I_{r k(1 h)}\right\rfloor+\left\lfloor I_{r k(1 h)}\right\rfloor
$$

where: 


$$
\begin{aligned}
& {\left[I_{r k(1)}\right]=\sum_{h=1}^{\infty} I_{r k}^{h p}\left[\begin{array}{c}
\cos \left(s_{(h)} \omega_{s} t+h p k \alpha_{r}-h p \varphi\right) \\
\vdots
\end{array}\right]_{k=0,1, \ldots, n_{b}-1}} \\
& {\left[I_{r k(1)}\right]=\sum_{h=1}^{\infty} I_{r k}^{h p}\left[\begin{array}{c}
\cos \left(s_{(h)} \omega_{s} t+h p k \alpha_{r}-h p \varphi\right) \\
\vdots
\end{array}\right]_{k=0,1, \ldots, n_{b}-1}} \\
& \vdots \\
& {\left[I_{r k(3)}\right]=\sum_{h=1}^{\infty} I_{r k}^{h p-1}\left[\begin{array}{c}
\cos \left(s_{(h)} \omega_{s} t+((h p-1) \mp 2 p) k \alpha_{r} \mp \lambda 2 \pi f_{\mathrm{int}}-h p \varphi\right) \\
\vdots
\end{array}\right]_{k=0,1, \ldots, n_{b}-1}}
\end{aligned}
$$

All the harmonics induced in the rotor current have their images at the stator current. From there, and following the same previous steps, we can write the derivative of the stator flux as follows:

$$
\frac{d\left[\psi_{s a}\right]}{d t}=\left[L_{s}\right] \frac{d\left[I_{s a}\right]}{d t}+\frac{d\left[\psi_{s a 1}\right]}{d t}+\frac{d\left[\psi_{s a 2}\right]}{d t}+\frac{d\left[\psi_{s a 3}\right]}{d t}
$$

were:

$$
\left\{\frac{d\left[\psi_{s a 1}\right]}{d t}=\frac{d\left[L_{(k q h)}^{s r}\right]\left[I_{r k(1)}(h p)\right]}{d t}, \frac{d\left[\psi_{s a 2}\right]}{d t}=\frac{d\left[L_{(k q h)}^{s r}\right]\left[I_{r k(2)}(h p)\right]}{d t}, \frac{d\left[\psi_{s a 3}\right]}{d t}=\frac{d\left[L_{(k q h)}^{s r}\right]\left[I_{r k(3)}(h p)\right]}{d t}\right\}
$$

After development, we find that the terms in (40) are always null except for the follow harmonic orders [29], [30]:

$$
\left\{h=1, \mathrm{~h}=\left(\frac{\lambda \mathrm{n}_{\mathrm{b}}}{p} \mp 1\right)_{\lambda=1,2, \ldots}, \mathrm{h}=\left(\frac{\lambda \mathrm{n}_{\mathrm{b}} \mp 1}{p} \mp 1\right)_{\lambda=1,2, \ldots}, \mathrm{h}=\left(\frac{\lambda \mathrm{n}_{\mathrm{b}} \mp 2}{p} \mp 1\right)_{\lambda=1,2, . .}\right\}
$$

The voltages induced in the stator produce a new series of high frequency in the stator current, and the expression of these components are:

$$
f_{\text {int }-e c c}=\left(\frac{\lambda n_{b} \mp 2}{p}(1-s) \pm 1\right) f_{s} \mp \frac{1}{p} f_{r} \mp k f_{\text {int }} \quad \lambda=1,2,3, ., k=1,2,3, .
$$

The voltages induced in the stator produce a new series of high frequency in the stator current, and the expression of these components are:

$$
f_{\text {int }-e c c}=\left(\frac{\lambda n_{b} \mp 2}{p}(1-s) \pm 1\right) f_{s} \mp \frac{1}{p} f_{r} \mp k f_{\text {int }} \quad \lambda=1,2,3, ., k=1,2,3, .
$$

The Table 1 shows the new expression of the frequencies found by our approach, and that found by the approach of Blodt.

Table 1. Stator Current Inner Race Bearing Fault Frequency

\begin{tabular}{cc}
\hline Inner race bearing fault frequency \\
\hline The Blödt approach & $f_{\text {int-ecc }}=f_{s} \mp f_{r} \mp k f_{\text {int }}$ \\
The present approach $\quad f_{\text {int-ecc }}=\left[\frac{\lambda n_{b}}{P}(1-s) \mp 1\right] f_{s} \mp \frac{1}{p} f_{r} \mp k f_{\text {int }}$ \\
\hline
\end{tabular}




\section{TEST LABORATORY}

A test bench have been set up at Ampere Laboratory CNRS,UMR 5005 of Claude Bernard university Lyon 1, France, in order to validate the previously discussed analytical model. The Tested machine is a star connected induction motor. Ratings of the tested motor are a $5.5 \mathrm{~kW}$ three-phase induction machine with 48 stator slots, 28 rotor bars, and 2 pair poles from 5 Leroy Somer manufacturer,LS 132S with a protection factor of 55 (protection against dust and against water jets), nominal motor speed is $1440 \mathrm{tr} / \mathrm{min}$ for $11.4 \mathrm{~A}$ and $\cos \varphi=0.84$. Stator phase resistance $1.315 \Omega$. It has two NUP 206 type rolling ball bearings with 13 balls.

The defect was simulated on a roller bearing by the addition of a contaminant (cement powder). The inner ring fault (a stripe on the inner ring) was carried out on 3 levels of severity as shown in Figure 7.
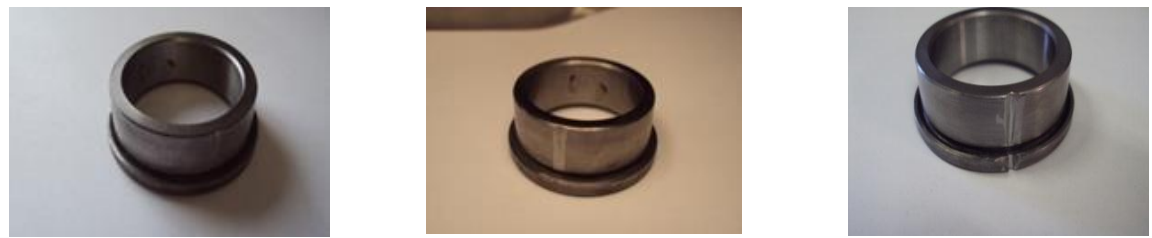

Figure 7. Failure on the inner ring of the bearing NUP 206 (a-Level 1/3, b- Level 2/3 and c- Level 3/3)

For a load speed of $1406 \mathrm{tr} / \mathrm{min}$ for a level (1/3) of defective bearing, $1423 \mathrm{tr} / \mathrm{min}$ for the level (2/3) , and $1420 \mathrm{tr} / \mathrm{min}$ for the levels (3/3) and for $1420 \mathrm{tr} / \mathrm{min}$ the safe bearing - Bearing NUP 206, and using equation (53), it sets the table for the frequencies detected a small angle default $(\gamma)$ so a hole, or a larger defect angle therefore for our case a groove in the inner ring.

Indeed, for any motor we always distinguish visible small eccentricity rotor frequencies, which explain the existence of some specific harmonics of the inner race bearing fault even for a healthy motor as shown in Figures 8 (a), (b), (c), Figures 9 (a), (b), (c), when the motor is tested with a defect angle at level $(1 / 3)$.

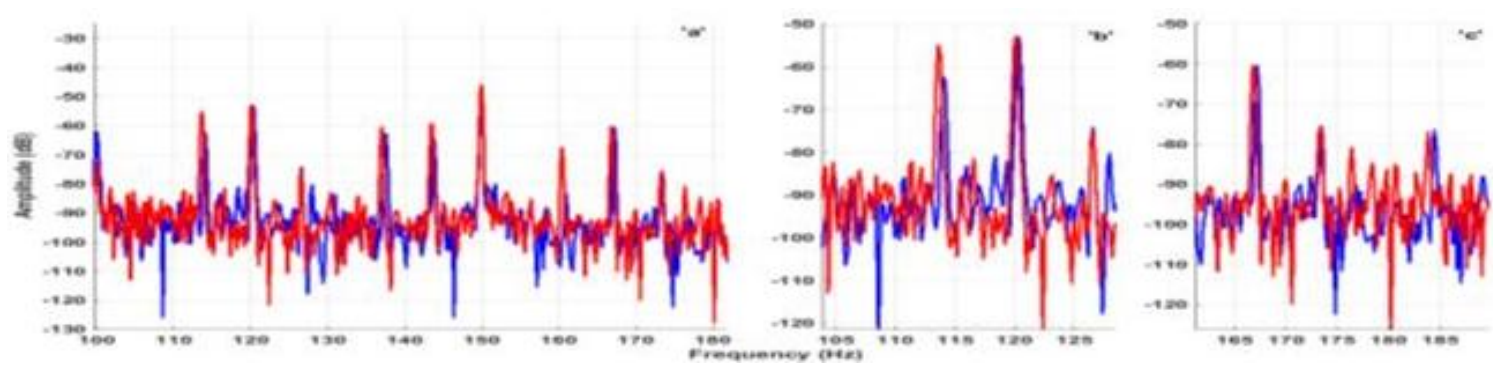

Figure 8. (a) Experimental FFT spectrum of the stator current under healthy condition (Blue), and faulty condition (Red), s=0:061. Level (1/3) between $100 \mathrm{~Hz}$ and $180 \mathrm{~Hz}$ (Zoom on (b) $113.03 \mathrm{~Hz}$, (c) $172.21 \mathrm{~Hz}$ )

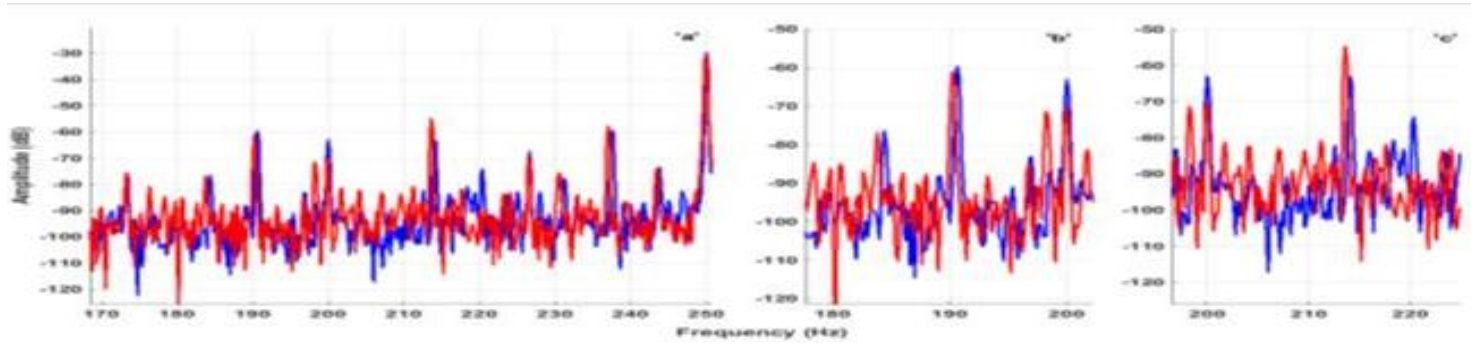

Figure 9. (a) Experimental FFT spectrum of the stator current under healthy condition (Blue), and faulty condition (Red), s=0:061. Level (1/3) between 170 and 250 (Zoom on (b) $189.56 \mathrm{~Hz}$, (c) $213.03 \mathrm{~Hz})$ 
This group of harmonics is summarized in Table 2 .

Table 2. Specific Harmonics of the Inner Race Bearing Fault in Stator Current (Level 1/3)

\begin{tabular}{ccc}
\hline$f_{\text {int }-e c c}=\left(\frac{\lambda N}{P}(1-s)-1\right) f_{s}-k f_{\text {int }}-\frac{1}{P} f_{r}$ \\
& Healthy & Faulty \\
\hline$\lambda=1, \mathrm{k}=3$ & $173.9 \mathrm{~Hz}$ & $172.21 \mathrm{~Hz}$ \\
$\lambda=3, \mathrm{k}=10$ & $114.43 \mathrm{~Hz}$ & $113.03 \mathrm{~Hz}$ \\
& $214.43 \mathrm{~Hz}$ & $213.03 \mathrm{~Hz}$ \\
& $190.76 \mathrm{~Hz}$ & $189.56 \mathrm{~Hz}$ \\
\hline
\end{tabular}

The spectrum of the faulty condition case (Level 1/3) contains new harmonic components (162.30 Hz, $262.30 \mathrm{~Hz}, 202.83 \mathrm{~Hz}$ and $302.83 \mathrm{~Hz}$ ) as illustrated in Figures 10 (a), (b), (c) and Figures 11 (a), (b), (c).

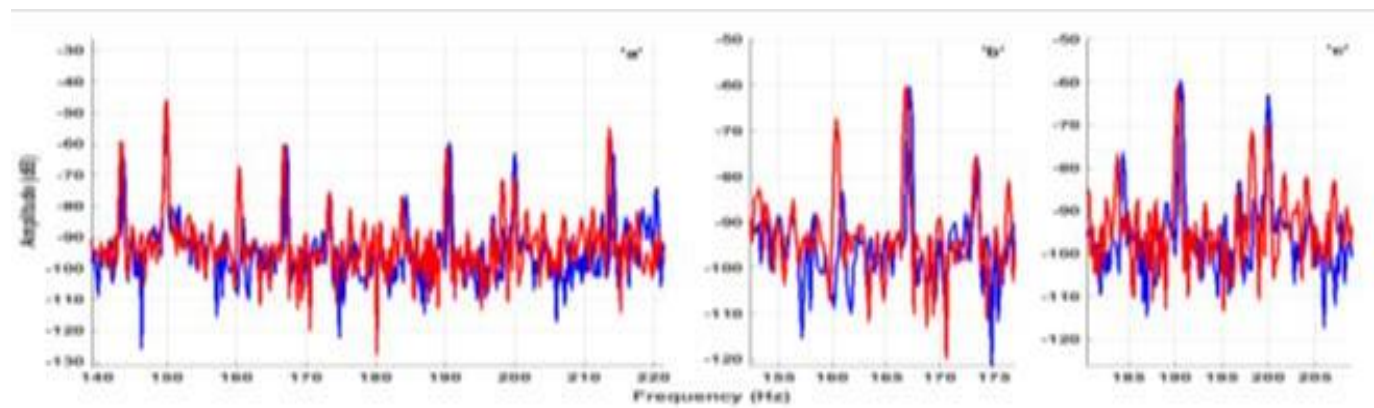

Figure 10. (a) Experimental FFT spectrum of the stator current under healthy condition (Blue), and faulty condition (Red) s=0.063. Level (1/3) between $140 \mathrm{~Hz}$ and $220 \mathrm{~Hz}$ (Zoom on (b) $159.28 \mathrm{~Hz}$, (c) $198.48 \mathrm{~Hz}$ )

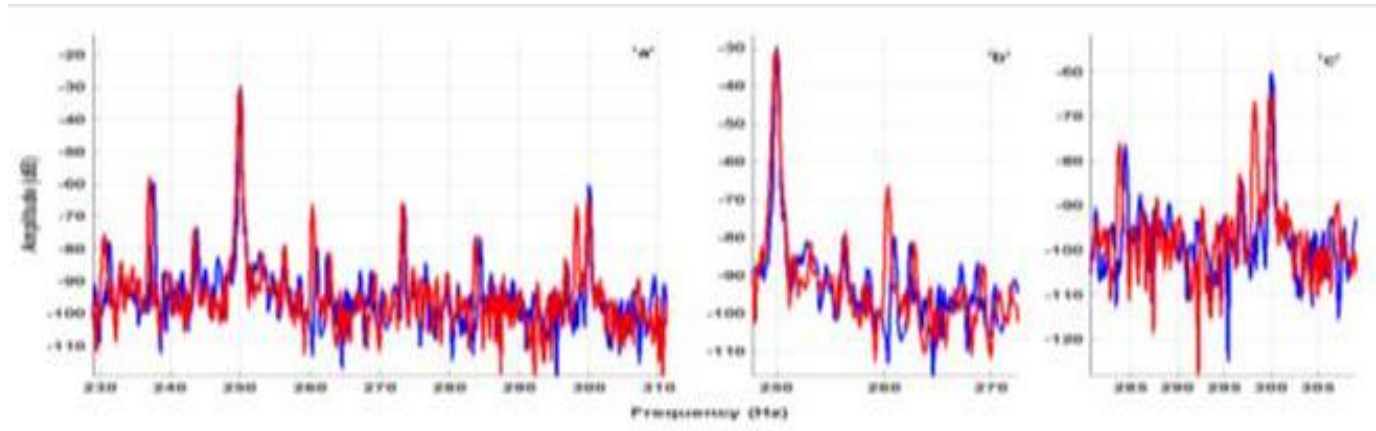

Figure 11. (a) Experimental FFT spectrum of the stator current under healthy condition (Blue), and faulty condition (Red) s=0.063. Level (1/3) between $230 \mathrm{~Hz}$ and $310 \mathrm{~Hz}$ (Zoom on (b) $259.28 \mathrm{~Hz}$, (c) $298.48 \mathrm{~Hz}$ )

This group of harmonics is summarized in Table 3 .

Table 3. New Specific Harmonics of the Inner Race Bearing Fault in Stator Current (Level 1/3)

\begin{tabular}{|c|c|}
\hline & $f_{\text {int-ecc }}=\left(\frac{\lambda N}{P}(1-s)-1\right) f_{s}-k f_{\text {int }}-\frac{1}{P} f_{r}$ \\
\hline$\lambda=2, \mathrm{k}=6$ & $\begin{array}{c}f_{\text {int-ecc }}=(28(1-s)-1) f_{s}-6 f_{\text {int }}-1 / 2 f_{r}=159.28 \mathrm{~Hz} \\
f_{\text {int }-e c c}=(28(1-s)+1) f_{s}-6 f_{\text {int }}+1 / 2 f_{r}=259.28 H z\end{array}$ \\
\hline$\lambda=4, k=13$ & $\begin{array}{l}f_{\text {int }-e c c}=(56(1-s)-1) f_{s}-13 f_{\text {int }}-1 / 2 f_{r}=198.48 H z \\
f_{\text {int }-e c c}=(56(1-s)+1) f_{s}-13 f_{\text {int }}-1 / 2 f_{r}=298.48 H z\end{array}$ \\
\hline
\end{tabular}


The motor is now tested with a few significant increase in the degree of severity (level 2/3) from the previous (level 1/3), but with a clear reduction of the load relative to the previous test $(1423 \mathrm{Tr} / \mathrm{min}$ instead of $1406 \mathrm{Tr} / \mathrm{min})$

Note that the amplitudes of the specific harmonics of the fault inner ring have decreased due to the reduction of the load, against the minimal increase in severity had no impact on either the amplitude of the harmonic and on the new generation of harmonics. The Figures 12 (a), (b), (c) show an example of a pair of harmonics (159.28 Hz and $259.28 \mathrm{~Hz})$.

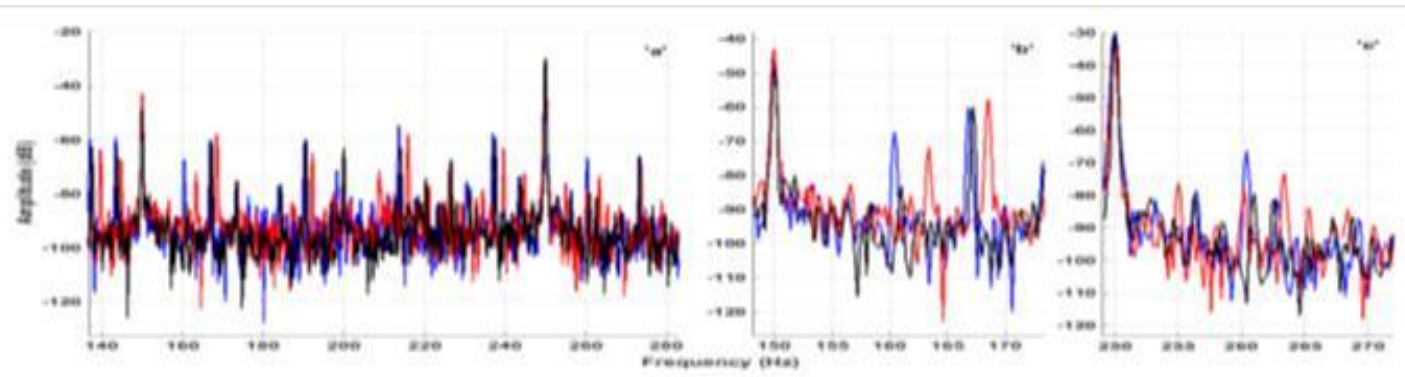

Figure 12. (a) Experimental FFT spectrum of the stator current under Healthy condition (Black), faulty condition Level (1/3) (Blue)s $=0.063$, and Level $(2 / 3)($ red)s $=0.051$ between $150 \mathrm{~Hz}$ and $280 \mathrm{~Hz}$ (Zoom on (b) $159.28 \mathrm{~Hz}-259.28 \mathrm{~Hz}$ Level (1/3) and (c) $162.73 \mathrm{~Hz}-262.73 \mathrm{~Hz}$ Level (2/3))

This pair of harmonics is summarized in Table 4.

Table 4. New Specific Harmonics of the Inner Race Bearing Fault in Stator Current (Level 1/3 and 2/3)

\begin{tabular}{ccc}
\hline$f_{\text {int }-e c c}=\left(\frac{\lambda N}{P}(1-s)-1\right) f_{s}-k f_{\text {int }}-\frac{1}{P} f_{r}$ \\
\hline \multirow{2}{*}{$\lambda=2, \mathrm{k}=6$} & Level 1/3 & Level $3 / 3$ \\
& $159.28 \mathrm{~Hz}$ & $162.3 \mathrm{~Hz}$ \\
\multirow{2}{*}{$\lambda=4, \mathrm{k}=13$} & $259.28 \mathrm{~Hz}$ & $262.3 \mathrm{~Hz}$ \\
& $198.48 \mathrm{~Hz}$ & $202.83 \mathrm{~Hz}$ \\
& $298.48 \mathrm{~Hz}$ & $302.83 \mathrm{~Hz}$ \\
\hline
\end{tabular}

The motor is tested again under the same conditions monitoring for healthy case (load speed 1420 $\mathrm{Tr} / \mathrm{min})$, with increasing the defect angle to level (3/3).

Note that despite the decrease of the load from the level (1/3), the inner race bearing fault harmonics do not lose their amplitudes and remain visible, which shows the influence of the increase angle fault confirming that which was predicted in section III. Some examples show this difference in Figures 13 (a), (b), (c) and Figures 14 (a), (b), (c).

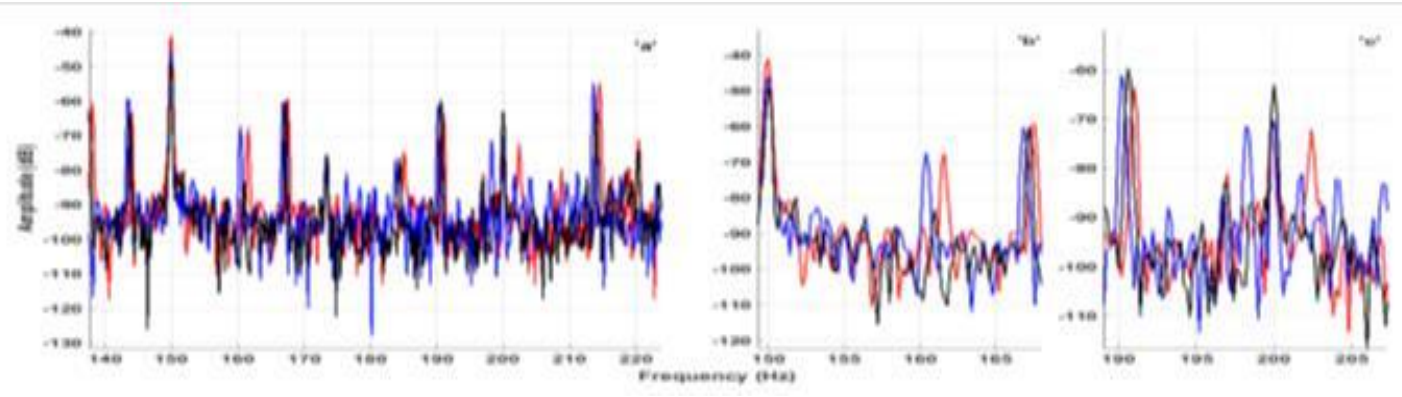

Figure 13. (a)Experimental FFT spectrum of the stator current under Healthy condition (Black) s=0.053, faulty condition Level (1/3) (Blue)s $=0.063$, and faulty condition Level $(3 / 3)$ (red)s $=0.053$ between $140 \mathrm{~Hz}$ and $220 \mathrm{~Hz}$. (Zoom on (b) $159.28 \mathrm{~Hz}-198.48 \mathrm{~Hz}$ Level (1/3) and (c) $162.3 \mathrm{~Hz}-202.63 \mathrm{~Hz} \mathrm{Level} \mathrm{(3/3))}$ 

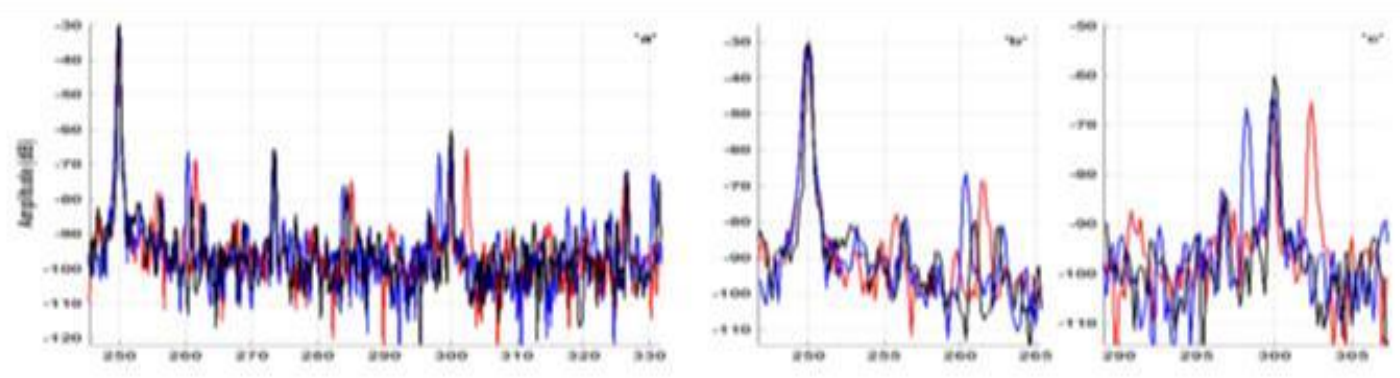

Figure 14. (a) Experimental FFT spectrum of the stator current under Healthy condition (Black), faulty condition Level (1/3) (Blue)s $=0.063$, and faulty condition Level $(3 / 3)$ (red)s $=0.053$ between $250 \mathrm{~Hz}$ and $330 \mathrm{~Hz}$ (Zoom on (b) $259.28 \mathrm{~Hz}-298.48 \mathrm{~Hz}$ Level (1/3) and (c) $262.3 \mathrm{~Hz}-302.63 \mathrm{~Hz}$ Level (3/3))

This two pairs of harmonics are summarized in Table 5.

Table 5. New Specific Harmonics of the Inner Race Bearing Fault in Stator Current (Level 1/3 and 3/3)

\begin{tabular}{ccc}
\hline$f_{\text {int }-e c c}=((\lambda N / p)(1-s)-1) f_{s}-k f_{\text {int }}-(1 / p) f_{r}$ \\
\hline \multirow{3}{*}{$\lambda=2, \mathrm{k}=6$} & Level $1 / 3$ & Level $2 / 3$ \\
& $159.28 \mathrm{~Hz}$ & $162.73 \mathrm{~Hz}$ \\
& $259.28 \mathrm{~Hz}$ & $262.73 \mathrm{~Hz}$ \\
\hline
\end{tabular}

\section{CONCLUSION}

A new comprehensive method for the calculation of different inductance values of an induction motor based on winding function approaches is presented. Inductances of healthy machine as well as dynamic eccentricity and inner race bearing fault is calculated and studied. The effect of the defect angle is verified. It is also shown that due to the air-gap asymmetry such as dynamic eccentricity or the inner raceway defect, the values of inductance coefficients have considerable variations with respect to the healthy condition and this last was applied for the study and detection of this fault.

The experimental results which show current spectra of an induction machine with inner race defects, and are used to verify the new expression of the characteristic frequency of this fault. The experimental results clearly illustrate that the Stator Current Signature Analysis can be used to identify the presence of a bearing fault.

\section{REFERENCES}

[1] Li Meng, Wang Miao, Wang Chunguang, "Research on SVM Classification Performance in Rolling Bearing Diagnosis", International Conference on Intelligent Computation Technology and Automation, ICICTA' 010, Changsha, 11-12 May 2010, Vol. 3, pp132 - 135, 2010.

[2] Antoine Picot, Ziad Obeid, Jeremi Regnier and Pascal Maussion, Sylvain Poignant and Olivier Darnis., "Bearing fault Detection in Synchronous Machine based on the Statistical Analysis of Stator Current”, IECON'012, Dec. 2012, pp 3862-3867,IEEE 2012.

[3] Sarah El-Samad, Amani Raad, "Rolling Bearing Diagnosis using Cyclostationary tools and neural networks"2nd International conference on Advances in Computational Tools for Engineering applications (ACTEA), pp 101-105IEEE 2012.

[4] Weixing He, Chunfang Yin, Xiaoping Chen, "Nonlinear Methods for Rolling Bearing Fault Diagnosis" Ninth International conference on Natural Computation (ICNC), Mar. 2013, pp 168-172- IEEE 2013.

[5] Jun Ma, Juande Wu, Xiaodong Wang. Yugang Fan, "The Mixed Fault Detection For Rolling Bearings Based on ICA-Teager" Control and Decision Conference (2014 CCDC), The 26th Chinese, pp 2881-2885- IEEE. 2014

[6] Liying Jiang, Guangting Gong, Yanpeng Zhang, Zhipeng Liu, Jianguo Cui, "Fault Detection of Rolling Bearing Based on EMD-DPCA" Control and Decision Conference (2014 CCDC), The 26th Chinese, pp 3207-3211- IEEE. 2014

[7] Jason R. Stack, Thomas G. Habetler and Ronald G. Harley, "Fault Classification and Fault Signature Production for Rolling Element Bearings in Electric Machines", IEEE Transactions on Industry applications, Vol. 40, No. 3, pp. 735-739, May/June 2004.

[8] Zhenhe Wang, Shaocong Guo Fuyuan Zhang, "A Mathematical Model Of Magnetic Bearing Control Based On Fuzzy Logic And Single Neuron", Asia-Pacific Conference on Wearable Computing Systems pp 371-374- IEEE 2010 .

Analytical Model of Cage Induction Machine Dedicated to the Study of the Inner Race ... (Hadjami M) 
[9] R. R. Schoen, T. G. Habetler, F. Kamran, and R. Bartheld, "Motor bearing damage detection using stator current monitoring," IEEE Transactions on Industry applications, vol. 31, no. 6, pp. 1274-1279, Nov./Dec. 1995

[10] Anindita Adikaputri Vinaya, Dhany Arifianto, "Multi-way Array Decomposition on Acoustic Source Separation for Fault Diagnosis of a Motor-Pump System", International Journal of Electrical and Computer Engineering (IJECE), Vol 7, No 6: December 2017

[11] Ciprian Harlişca, Loránd Szabó, Lucia Frosini, Andrea Albini“Diagnosis of Rolling Bearings Faults in Electric Machines through Stray Magnetic Flux Monitoring", The 8th International Symposium On Advanced Topics In Electrical Engeneering May 23-25, pp 2068-7966, IEEE 2013.

[12] Lucia Frosini Ezio Bassi Christian Gazzaniga, "Effect of the Bearings Faults on the Efficiency of the Induction Motors", Industrial Electronics, 2008. IECON 2008. 34th Annual Conference of IEEE pp 1167-1172- IEEE 2008.

[13] Martin Blödt, Pierre Granjon, Bertrand Raison, and Gilles Rostaing, "Models for Bearing Damage Detection in Induction Motors Using Stator Current Monitoring", IEEE Transactios On Industrial Electronics, Vol. 55, No. 4, APRIL. 2008

[14] Martin Blödt, Marie Chabert, Jérémi Regnier, and Jean Faucher,“ Mechanical Load Fault Detection in Induction Motors by Stator CurrentTime-Frequency Analysis”, IEEE Transactions On Industry Applications, Vol. 42, No. 6, Nov/Dec 2006

[15] Mawuena SEGLA, Shaoping WANG, Fang WANG, "Bearing Fault Diagnosis with an Improved High Frequency ResonanceTechnique”, Industrial Informatics (INDIN), 2012 10th IEEE International Conference on IEEE, pp. 580-585. IEEE 2012

[16] Hong Zheng, Lei Zhou,"Rolling element bearing fault diagnosis based on supportvectormachine", Consumer Electronics, Communications and Networks (CECNet), 2012 2nd International Conference on IEEE, pp. 544-547. IEEE 2012

[17] L. Eren, and M. J. Devaney, "Bearing damage detection via wavelet packet decomposition of the stator current,"IEEE Transactions on Instrumentation and Measurement, vol. 53, No. 2, pp. 431 - 436, April. 2004.

[18] Lucia Frosini Ezio Bassi, "Stator Current and Motor Efficiency as indicators for Different Types of Bearing Faults in Induction Motors", IEEE Transactios On Industrial Electronics, vol. 57, No: 1, pp. 244 - 251, 2010.

[19] Shady S. Refaat, Haitham Abu-Rub, M. S. Saad, E. M. Aboul-Zahab and Atif Iqbal "ANN-Based for Detection, Diagnosis the Bearing Fault for Three Phase Induction Motors Using Current Signal", Industrial Technology (ICIT), 2013 International Conference on IEEE, pp 253-258. IEEE 2013.

[20] Sukhjeet Singh, Amit Kumar, Navin Kumar, "Motor Current Signature Analysis for Bearing Fault Detection in Mechanical Systems", 3rd International Conference on Materials Processing and Characterisation (ICMPC 2014). Elsevier.

[21] Valéria C. M. N. Leite, Jonas Guedes Borges da Silva, Giscard Francimeire Cintra Veloso,Luiz Eduardo Borges da Silva, Germano Lambert-Torres, fellow, Erik Leandro Bonaldi, and Levy Ely de Lacerda de Oliveira, "Detection of Localized Bearing Faults in Induction Machines by Spectral Kurtosis and Envelope Analysis of Stator Current", IEEE Transactions On Industrial Electronics, Vol. 62, No. 3, March 2015

[22] Alaa Abdulhady Jaber, Robert Bicker "Design of a Wireless Sensor Node for Vibration Monitoring of Industrial Machinery" International Journal of Electrical and Computer Engineering (IJECE), Vol 6, No 2: April 2016

[23] Hadjami M, Khezzar A, Oumaamar M.E.K, Razik H, Rezzoug A. "Analytical Model of Cage Induction Machine Dedicated to the Study of Axial Non-uniformities", International Symposium on Diagnostics for Electric Machines, Power Electronics \& Drives (SDEMPED), IEEE 2011.

[24] S. Braun and S. G. Braun, Mechanical signature analysis: theory and applications. Burlington, Massachusetts, USA: Academic Press, 1986.

[25] Bossio, G.; De Angelo, C.; Solsona, J.; Garcia, G.; Valla, M.I.; "A 2-D model of the induction machine: an extension of the modified winding function approach", IEEE Transaction on Energy Conversion, vol.19.No 1, pp. 144-150, March. 2004.

[26] Bossio, G.; De Angelo, C.; Solsona, J.; Garcia, G.O.; Valla, M.I.; Application of an Additional Excitation in Inverter-Fed Induction Motors for Air-Gap Eccentricity Diagnosis, IEEE Transaction on Energy Conversion ,vol.21. No 6, pp. 839-847, Dec. 2006.

[27] Mohammad Jannati, Tole Sutikno, Nik Rumzi Nik Idris, Mohd Junaidi Abdul Aziz "Modeling of Balanced and Unbalanced Three-Phase Induction Motor under Balanced and Unbalanced Supply Based on Winding Function Method" International Journal of Electrical and Computer Engineering (IJECE), Vol 5, No 4: August 2015

[28] Khezzar, M. Hadjami, N. Bessous, M.E.K. Oumaamar, H Razik“Accurate Modelling of Cage Induction Machine with Analytical Evaluation of Inductances" 34th Annual Conference of the IEEE Industrial Electronics Society, IECON'08, Orlando, Floride, USA. Nov 10-13, pp. 1112 - 1117, IEEE 2008.

[29] Maouche, Y.; Louze, L.; Oumaamar, M.E.-K.; A. Khezzar "Analytical model of dynamic air-gap eccentricity in three-phase squirrel cage induction motor".IEEE International Conference on Power and Energy (PECon), pp.282 287, IEEE 2014.

[30] M. Y. Kaikaa, M. Hadjami and A. Khezzar "Effects of the Simultaneous Presence of Static Eccentricity and Broken Rotor Bars on the Stator Current of Induction Machine" IEEE Tranactions on Industrial Electronics, 2014. Vol.61. No 5, pp. 2452-2463, and No 6, pp. 2942. May 2014. 


\section{BIOGRAPHIES OF AUTHORS}
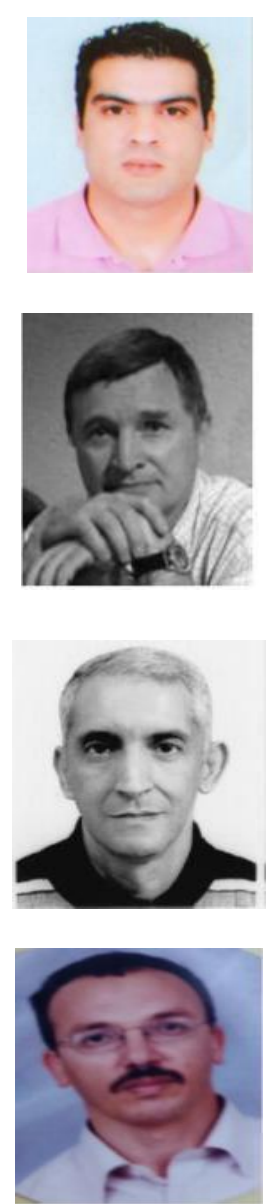

Marouane Hadjami was born in 1974. He recieved the B.sc. degree in electrical engeneering from the university of Annaba, Annaba, Algeria, in 1998 and the M.sc. degree from the university of Skikda, Skikda, Algeria, in 2008. He is currently working toward The Ph.D. degree on the diagnosis of faults of induction machines at Laboratoire d'Electrotechnique de Constantine (LEC) laboratory Mentouri University Constantine, Algeria. He is lecturer at ENSET School, Skikda, Algeria, in the departement of electrical engeneering.

Hubert Razik (M'98-SM'03) received the M.Sc. degree in electrical engineering from the Ecole Normale Superieure, Cachan, France, in 1987, the Ph.D. degree in electrical engineering from the Institut Polytechnique de Lorraine, Nancy, France, in 1991, and the Habilitation to Supervise Research from the Universite Henri Poincare, Nancy, France, in 2000. In 1993, he became an Associate Professor and, since November 1, 2009, he is a Professor of Electrical Engineering with the Universite Claude Bernard Lyon 1, Villeurbanne, France Since January 1, 2016, he is Deputy Director of the Laboratory AMPERE - UMR 5005. His research interests include modeling, control, and monitoring conditions of electrical systems.

Mohamed El Kamel Oumaamar received the B.Sc. degree from the University of Annaba, Annaba, Algeria, in 1987 and the M.Sc. degree, in 2004, and the Ph.D. degree in electrgical engineering, 2010, from Mentouri University, Constantine. Algeria. His main research interests are on the diagnosis of faults of induction machines at Laboratoire d'Electrotechnique de Constantine (LEC) Laboratory, Mentouri University, Constantine, Algeria. As a Lecturer with the Department of Electrical Engineering, University Mentouri of Constantine.

Abdelmalek Khezzar (M’07) was born in Batna, Algeria, in 1969. He received the Engineer degree in electrical engineering from Batna University, Batna, in 1993 and the Ph.D. degree in electrical engineering from the Institut National Polytechnique de Loraine, Nancy, France, in 1997. In 2000, he joined Frères Mentouri Constantine 1 University, Constantine, Algeria, as a Lecturer with the Department of Electrical Engineering, where he has been a Full Professor since December 2008 and the Director of the Laboratoire d'Electrotechnique de Constantine in April 2009. His main research interests are power electronics, drives, and analysis of electrical machine, with special emphasis on fault diagnosis. 